\title{
A Study on Neck Injuries in Deaths Due to Hanging on Basis of Epidemiological Factors
}

\author{
Ashok Singh Dangus ${ }^{1}$, Santosh Kumar Soni ${ }^{2}$, Ranjan Mathur ${ }^{3}$, Jitendra Acharya ${ }^{4}$ \\ ${ }^{1}$ Assistant Professor, Department of Forensic Medicine and Toxicology, S. N. Medical College, Jodhpur, Rajasthan, India, ${ }^{2}$ Senior Demonstrator, Department of \\ Forensic Medicine and Toxicology, S. N. Medical College, Jodhpur, Rajasthan, India, ${ }^{3}$ Senior Professor and Head, Department of Dentistry, S. P. Medical College, \\ Bikaner, Rajasthan, India, ${ }^{4}$ Senior Demonstrator, Department of Dentistry, S. P. Medical College, Bikaner, Rajasthan, India.
}

\section{Abstract}

Background: Most of the hanging cases are consider as suicidal until the homicidal and accidental are prove, because both homicidal and accidental hanging are rare. In these cases a watchful forensic examination plays an important role to determine the ante mortem character of the lesion and to exclude causes of hanging other than suicidal hanging. Aim: This study done to know the internal and external assessment findings among hanging cases. Subjects and Methods: Hanging deaths with external neck injuries along with ligature mark were included in this study. In this study a total of 60 cases of deaths due to hanging, was subjected to medico legal autopsy. Results: Most of the cases were observed in the age group of 21-40 years i.e., 41 (69.4\%) out of 59 hanging deaths. Out of 59 deaths, 32 (54.2\%) were females and 27 $(45.7 \%)$ were males. Among neck structure injuries, majority of hanging cases had rupture / contusion of sternocleidomastoid and other strap muscles of neck, it was 57.6\%. 33.8\% cases had carotid intimal tear, 5\% cases showed hyoid bone fracture and 3.3\% thyroid cartilage. No fractures noted in Cricoid cartilage and cervical vertebra. Conclusion: Social awareness, problem solving and family support of most common age group is extremely necessary.

Keywords: Hanging, Neck Structures.

Corresponding Author: Dr. Santosh Kumar Soni, Senior Demonstrator, Department of Forensic Medicine and Toxicology, S. N. Medical College, Jodhpur, Rajasthan, India.

Received: June 2019

Accepted: June 2019

\section{Introduction}

Mainly the hanging cases are measured as suicidal until the homicidal and accidental are proved, because both homicidal and accidental hanging are rare. In these cases a cautiously forensic examination plays an important role to determine the ante mortem character of the lesion and to exclude causes of hanging other than suicidal hanging. Synonym of hanging is self-suspension. ${ }^{[1]}$ Neck has many important structures which are crowded together in the neck such as muscles, glands, trachea, oesophagus, larynx, vessels, nerves, vertebrae etc. ${ }^{[2]}$ emblematic hanging is described when the point of suspension is over the centre of the occipital; the vessels of neck become occluded to the maximum. If the point of suspension is anywhere else, then it is called as atypical hanging. Worldwide, in the past 45 years suicide rate have increased $60 \%$ and the suicide rate is 16 per 1,00,000 population. Approximately for every 40 seconds, one person dies by suicide globally. $1.8 \%$ of worldwide deaths are suicides. ${ }^{[3]}$ frequent reasons for hanging are loss of property, financial losses, poverty, and disgust with life, love failure, passion, physical and mental sufferings, failures in many aspects, marital problems, and religious mania. These Hanging causes vary from country to country. ${ }^{[4]}$ This study done to know the internal and external examination findings among hanging cases.

\section{Subjects and Methods}

This Prospective study was conducted on cases suggestive of ante mortem hanging, in which the history and scene of crime examination report given by police and relatives of the deceased. This study conducted in 2017 (one year study) at Department of Forensic Medicine, S.N.Medical College Jodhpur. Cases with external neck injuries along with ligature mark were included in this study. In this study a total of 60 cases of deaths due to hanging, was subjected to medico legal autopsy. Details related to deceased persons including age, sex, place of hanging, reason for committing suicide, material used, type of knot, position of the knot, whether it was a complete or partial hanging, any blood stains or disturbance etc., at the scene of crime, presence of suicidal note and other relevant information were enquired from the police and relatives of the deceased. Subsequent to identification of the body, both external and internal findings were observed during post mortem examination. External findings such as injuries, saliva dribbling, signs of asphyxia, and signs of sphincter relaxation, Le facie sympathethic, hypostasis pattern, rigor mortis, and ligature mark study etc. After removing thoracic organs and brain, 
dissection of neck was done.

During dissection of neck, skin, subcutaneous tissue, anterior cervical strap muscles were examined for contusion or injury. Carotid artery and internal jugular vein were examined for tears, extravasation of blood or ruptures. The hyoid bone, thyroid cartilage and cricoid cartilage were examined for areas of blood extravasation and fracture.

Blood samples and viscera were collected for systemic toxicological analysis according to regular procedures. All samples were sent to our Forensic laboratory. Data Obtained was entered into spread excel sheet and analysed.

\section{Results}

A total of 59 cases of deaths observed due to hanging. Majority of the cases were observed in the age group of 2140 years i.e., $41(69.4 \%)$ out of 59 hanging deaths. Deaths due to hanging were not observed below the age group of 17 years. Among elders, one case of death observed in 71 years of age. Out of 59 deaths, $32(54.2 \%)$ were females and $27(45.7 \%)$ were males. Males and females were almost equally distributed in all the age groups [Table 1]. Nylon rope and cotton bed sheet were most commonly used ligature material followed by saree among hanging deaths. Nylon rope used in $15(25.4 \%)$ cases, cotton bed sheet used in $15(25.4 \%)$ cases, nylon saree used in $12(20.3 \%)$ cases, duppatta used in $7(11.8 \%)$ cases, electric wire used in 4 $(6.7 \%)$ cases, cotton lungi used in $4(6.7 \%)$ cases and coir rope used in $2(3.3 \%)$ cases.Out of 59 Hanging cases. 24 $(40.6 \%)$ were complete hanging and remaining 35 (59.3\%) were partial hanging. On assessment of ligature mark position over the neck, $50(84.7 \%)$ cases were seen above the thyroid cartilage and in only $9(15.2 \%)$ cases it was seen over and above thyroid cartilage. Incidence of position of knot was assessed. $36(61 \%)$ cases, knot was on left side of neck, 17 (28.8\%) cases knot was on back of neck, 4 (6.7\%) cases, and knot was on right side of neck and $2(3.3 \%)$ cases knot located below the chin.

Amongst neck structure injuries, majority of hanging cases had rupture / contusion of sternocleidomastoid and other strap muscles of neck, it was $57.6 \%$. 33.8\% cases had carotid intimal tear, $5 \%$ cases showed hyoid bone fracture and $3.3 \%$ thyroid cartilage. No fractures noted in Cricoid cartilage and cervical vertebra.

Table 1: Distribution of hanging deaths in different and age groups in relation to sex.

\begin{tabular}{|l|l|l|l|l|l|l|}
\hline Age in years & Male & $\boldsymbol{\%}$ & Female & \% & Total & \% \\
\hline $1-10$ & 0 & 0 & 0 & 0 & 0 & 0 \\
\hline $11-20$ & 4 & 6.7 & 9 & 15.2 & 13 & 22.03 \\
\hline $21-40$ & 20 & 33.8 & 21 & 35.5 & 41 & 69.4 \\
\hline $41-60$ & 3 & 5.08 & 1 & 1.6 & 4 & 6.7 \\
\hline$>60$ & 0 & 0 & 1 & 1.6 & 1 & 1.6 \\
\hline Total & 27 & 45.7 & 32 & 54.2 & 59 & 100 \\
\hline
\end{tabular}

\section{Discussion}

Hanging is a type of violent asphyxia death produced by suspending the body with a ligature around the neck, the toning force being the weight of the body or a part of body weight. ${ }^{[5]}$ Asphyxia is defined as "the physiologic and chemical state in a living organism in which acute lack of oxygen available for the cell metabolism is associated with inability to eliminate excess of carbon dioxide". ${ }^{66}$ Asphyxia or anoxia can occur due to interference with respiration by any mechanical obstruction in the air passages by constriction of air passages. ${ }^{[7]}$ General external appearances can found among hanging deaths are pale face, dilated pupils, cyanosis, eyes may be closed or partially open, protruded tongue, dribbling of saliva, penis may be engorged, post mortem staining will be well marked. 8 In the present study, majority of the cases were observed in the age group of 21-40 years i.e., 41 (69.4\%) out of 59 hanging deaths. Out of 59 deaths, $32(54.2 \%)$ were females and 27 $(45.7 \%)$ were males. Dr.Sharma BR et al did a retrospective study in 2005; documented male to female ratio of hanging cases was 2:1.[9] They have also noticed $46 \%$ of hanging cases were observed in the age group of 21-30 years. Nylon rope used in $15(25.4 \%)$ cases, cotton bed sheet used in 15 $(25.4 \%)$ cases, nylon saree used in 12 (20.3\%) cases, duppatta used in $7(11.8 \%)$ cases, electric wire used in 4 $(6.7 \%)$ cases, cotton lungi used in $4(6.7 \%)$ cases and coir rope used in $2(3.3 \%)$ cases as per this study. Dr.Sharma BR et al documented, $54.7 \%$ of hanging cases used soft material as a ligature and remaining $28.6 \%$ of hanging cases used hard material. Out of 59 hanging cases, 24 (40.6\%) were complete hanging and remaining $35(59.3 \%)$ were partial hanging. On assessment of ligature mark position over the neck, $50(84.7 \%)$ cases were seen above the thyroid cartilage and in only $9(15.2 \%)$ cases it was seen over and above thyroid cartilage. Reddy $\mathrm{KSN}$ et al, observed that ligature mark is situated above the level of thyroid cartilage, between larynx and chin in $80 \%$ of hanging cases, at the level of thyroid cartilage in about $15 \%$ cases and below the level of thyroid cartilage in about $5 \%$ cases. Naik SK et al found the ligature mark below the level of laryngeal prominence in $4.76 \%$ hanging cases and discontinuity of ligature mark was not noticed in $11.11 \%$ cases of suicidal hanging and $33.33 \%$ cases of homicidal hanging. ${ }^{[10]}$ As per this study out of 59 hanging deaths, 36 (61\%) cases, knot was on left side of neck, 17 (28.8\%) cases knot was on back of neck, $4(6.7 \%)$ cases, and knot was on right side of neck and $2(3.3 \%)$ cases knot located below the chin. Polson CJ et al stated as suspension by a knot below the chin is rare. ${ }^{[11]}$ Dr. Madan Mohan noted that in $46 \%$ of hanging cases, the knot is on the sid and in $4 \%$ cases on the back. ${ }^{[12]}$ Among neck structure injuries, majority of hanging cases had rupture / contusion of sternocleidomastoid and other strap muscles of neck, it was $57.6 \% .33 .8 \%$ cases had carotid intimal tear, $5 \%$ cases showed hyoid bone fracture and $3.3 \%$ thyroid cartilage. No fractures noted in Cricoid cartilage and cervical vertebra in this study. In complete hanging cases especially, contusion and rupture of platysma and sternocleidomastoid muscles can be noticed. ${ }^{[13]}$ Sivasuthan S et al noted $62 \%$ of cases with rupture of lower attachment of sternocleidomastoid muscle. ${ }^{[14]}$ Bhattacharji PK et al did a retrospective study on 175 cases of suicidal hanging, documented sternocleidomastoid muscle is the one most 
frequently gets injured. ${ }^{[15]}$ Tear of intima of carotid arteries is seen in $5-10 \%$ hanging cases, usually hyoid bone is intact in $80 \%$ of cases of hanging. ${ }^{[16]}$ Renjith et al reported out of 21 cases of hanging, $28.5 \%$ of hyoid bone fractures, all of them were males. ${ }^{[17]}$ In suicidal hanging cases, upper cervical vertebrae fracture occurs when the deceased jumps from a height and its fall is arrested by sudden jerk of a ligature. ${ }^{[8]}$ DiMaio et al did a study on 83 hanging cases, noted 10 cases $(12 \%)$ had fractures, of which 9 were thyroid cartilage fracture, especially superior horns, one was cervical spine fracture and none were hyoid bone fracture. ${ }^{[18]}$

\section{Conclusion}

Most of the hanging cases seen in younger age group, this may enforce a socioeconomic burden on society. Social awareness, problem solving and family support of most common age group is extremely necessary. Better way of preventing hanging cases is by creating social awareness for their problems, employment facilities for youth, psychiatric counselling.

\section{References}

1. Reddy KSN. Mechanical asphyxia. The essentials of Forensic Medicine and Toxicology, 27th ed., Medical book company, Hyderabad. 2008, pp. 299-318.

2. Richard S Snell. Clinical Anatomy by Regions- 8th ed., Wolters Kluwer (India), Pvt Ltd, New Delhi, 1993.

3. Ajdaic Gross V, Weiss MG, Ring M, Hepp V, Bopp M, Gutzwiller F et al. Methods of suicide: International suicide patterns derived from the WHO mortality database. Bull World Health Organ. 2008;86:72632.

4. Ali E, Maksud M, Zubyra SJ, Hossain S Md, Debnath PR, Alam A,
Chakrabarty PK. Suicide by hanging : study of 334 cases. Bangladesh Med J. 2014 May; 43 (2): 90-93.

5. Glaister J, Rentoul E. Asphyxia, Medical Jurisprudence and Toxicology, 12th ed., E\& S Livingstone, London. 1966, pp.166-187.

6. Krishan Vij. Asphyxial deaths. Textbook of Forensic Medicine and Toxicology- Pricnciples and practice, 3rd ed., Elsevier, 2008, pp. 179202.

7. Mukherjee JB. Violent Asphyxial Deaths. Forensic Medicine and Toxicology, Vol I Academic Publishers Calcutta, 1982, pp. 453-491.

8. Modi JP. Deaths from asphyxia. Modi's Medical Jurisprudence and Toxicology, 23rd ed., edited by Dr. K. Mathiharan, Prof Dr. Amrith Patnaik, Lexis Nexis Butterworths, 2006, pp. 565 - 590.

9. Sharma BR, Harish D, Virendar Pal Singh, Preminderjeet Singh. ligature mark on neck; How informative, a retrospective study of 95 deaths due to constriction of neck. JIAFM. 2005:27(1):10-15.

10. Naik SK. Obliquity Vs. Discontinuity of ligature mark in diagnosis of hanging - a comparative study, Anil Agarwal's internet. Journal of Forensic Medicine and Toxicology. 2006 Jan-Jun;7(1).

11. Polson CJ, Gee DJ, Knight B. Mechanical Asphyxia, The Essentials of Forensic Medicine, 4th ed., Pergamon Press, Oxford, 1985, pp. 351420.

12. Madan Mohan A. A Study of death due to hanging (An analysis of fifty cases of hanging), Thesis submitted to University of Calicut, 1982.

13. Parik CK. Violent Asphyxial Deaths. Parikh's Text book of Medical Jurisprudence Forensic Medicine and Toxicology - for classrooms and court rooms-, 6th ed., CBS publishers \& distributors, New Delhi, 2007, pp. $3.40-3.56$.

14. Sivasuthan S. Sternomastoid Rupture an index of antemortem hangingan autopsy study of 100 cases. Indian Internet J of Forensic Med. \& Toxicol. 2005;3(4).

15. Bhattacharji PK. Violent Asphyxia, Medicolegal Companion, 2nd ed., Aruna Publications, Lucknow. 1968, pp. 167-180.

16. NageshKumar Rao. Asphyxial deaths. Textbook of Forensic Medicine and Toxicology, 1st ed., Jaypee brothers, New Delhi, 2000, pp.157166.

17. Renjith C. A PostMortem Study of one hundred Hyoid bones, Thesis submitted to university of Calicut, 1984.

18. DiMaio VJ, DiMaio D. Asphyxia, Forensic Pathology, 2nd ed., CRC Press, London, 2001, pp 230-275.

Copyright: () the author(s), 2019. It is an open-access article distributed under the terms of the Creative Commons Attribution License (CC BY 4.0), which permits authors to retain ownership of the copyright for their content, and allow anyone to download, reuse, reprint, modify, distribute and/or copy the content as long as the original authors and source are cited.

How to cite this article: Dangus AS, Soni SK, Mathur R, Acharya J. A Study on Neck Injuries in Deaths Due to Hanging on Basis of Epidemiological Factors. Asian J. Med. Res. 2019;8(3):FM04-FM06.

DOI: dx.doi.org/10.21276/ajmr.2019.8.3.FM2

Source of Support: Nil, Conflict of Interest: None declared. 